\title{
Localized amyloidosis of the ureter: A case report and literature review
}

\author{
Xiaobo Ding, PhD; $;^{*}$ Xu Yan, PhD; Xiaobo Ma, PhD; ${ }_{i}^{+}$Chunxi Wang, PhD; $;^{\xi}$ Yujun Du, PhD; ${ }^{*}$ Haifeng Wang, PhD; \\ Yan Wang, PhD, ' Yanbo Wang, PhDs
}

*Department of Radiology, First Hospital of Jilin University, Changchun, China; †Department of Pathology, First Hospital of Jilin University, Changchun, China; §Department of Urology, First Hospital of Jilin University, Changchun, China; *Department of Nephrology, First Hospital of Jilin University, Changchun, China; „Department of Neurosurgery, First Hospital of Jilin University, Changchun, China

Cite as: Can Urol Assoc J 2013;7(11-12):e764-7. http://dx.doi.org/10.5489/cuaj.576

Published online November 8, 2013.

\section{Abstract}

Localized amyloidosis of the ureter is a rare disease and can easily be confused with a neoplasm. We report the case of a 55-year-old woman who presented with loin pain and painless gross hematuria. We also reviewed the English literature about localized ureteral amyloidosis. Middle-aged women were likely to suffer from this disorder. Loin pain and hematuria were the main clinical features. There were no specific performance on radiologic imaging and ureteral calcification was not widespread. Compared to upper ureter and middle ureter, the lower ureter was the easiest involved part. Nephroureterectomy was the predominant treatment. Biopsies via a ureteroscope prior to surgery or intraoperative frozen section examination, which yielded the diagnosis of amyloidosis, could help to avoid unnecessary surgery. The use of dimethyl sulfoxide or follow-up with serial imaging may become a promising treatment.

A myloidosis is a heterogeneous group of disorders in which amyloid substances are deposited extracellularly. It can be systemic or localized when affecting specific organs. ${ }^{1}$ Localized amyloid deposition in the urinary tract, especially of the ureter, is rare; the renal pelvis and bladder are the most common locations found clinically and radiologically. It is extremely difficult to clearly diagnose this disease preoperatively. Few cases of ureteral amyloidosis have been described. We present a case of localized ureteral amyloidosis and a comprehensive review of the literature. Written informed consent was obtained from the patient for publication of this case report and any accompanying images.

\section{Case report}

A 55-year-old woman was admitted to hospital with complaints of loin pain and painless gross hematuria for 2 days.
She had no history of urologic or chronic medical disorders. A physical examination showed slight tenderness and percussion pain in the left kidney district. All routine examinations were normal, except for hematuria and proteinuria. Cystoscopy performed during a period of hematuria showed bleeding from the left ureter. No tumours or stones were seen in the bladder. Ultrasound scanning demonstrated left hydronephrosis, hydroureter of the proximal-middle portion and obstruction of the lower ureter.

On un-enhanced computed tomography (CT), focal calcification (457 Hounsfield unity [HU]) was present on the ureter wall in the fourth vertebral level (Fig. 1) and a homogeneous soft tissue density mass (31-45 HU) was seen in the fifth vertebral level of the left ureter (Fig. 2). The length of lesion was about $22 \mathrm{~mm}$. Enhanced images showed a strip soft tissue density showing significant enhancement (44 HU). The length of the lesion was $85 \mathrm{~mm}$ (Fig. 3). No ureteral expansion was present below the distal lesion. Ureteral carcinoma was suspected, and radical left nephroureterectomy was scheduled. However, a perioperative frozen section examination showed the presence of amyloid. It was inevitable to perform nephrostomy if we chose a ureteral tumour resection because of long segment of the tumour. The patient finally elected to undergo left nephroureterectomy after our discussion with her and her family.

Grossly, the segment of the ureter was diffusely thickened and mildly rigid. Histology of the cross-section of the ureter revealed markedly thickened ureteric walls due to amorphous, pale eosinophilic, extracellular nodular deposits expanding the lamina propria and extending patchily into the muscularis propria as well as focally into the adventitia. The amorphous material exhibited apple-green birefringence under polarized light on Congo-red staining (Fig. 4), indicative of amyloidosis. No follow-up information was available for this patient. 


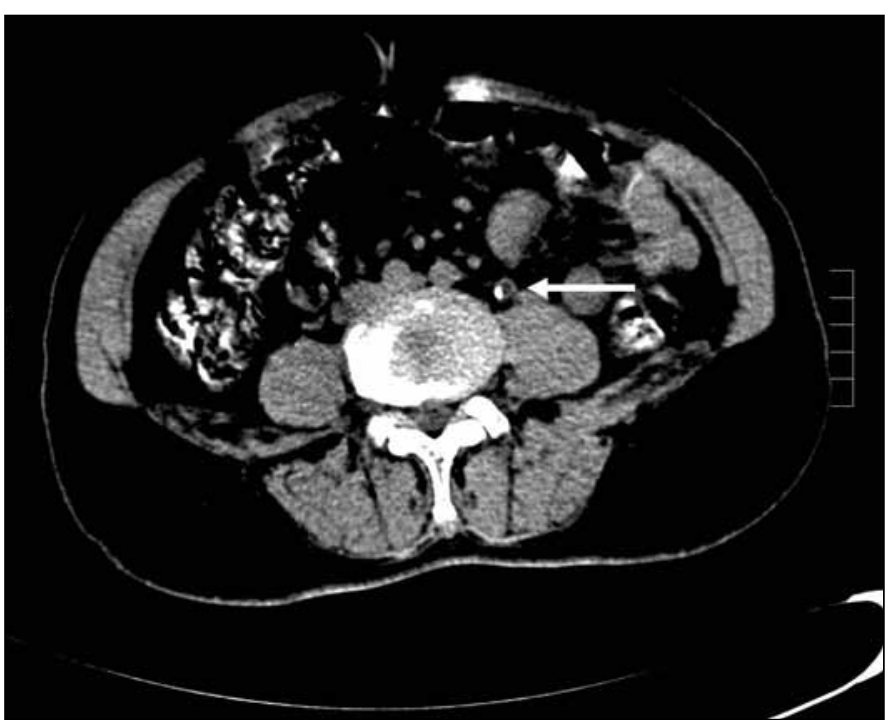

Fig. 1. A focal calcification was present on the ureter wall in the fourth vertebral level.

\section{Discussion}

Amyloidosis has an incidence of 8 per million people each year. ${ }^{2}$ The two major types include primary and secondary. ${ }^{3}$ Most cases of primary amyloidosis may be defined as amyloid immunoglobulin light chain (AL) disease. Primary AL amyloidosis has clonal B-cell dyscrasia, including multiple myelomas, B-cell lymphoma, Waldenström macroglobulinemia, or another plasma cell neoplasia. ${ }^{3,4}$ Bone marrow biopsy is required for all patients with $\mathrm{AL}$ amyloidosis to exclude overt multiple myeloma. Secondary amyloidosis most often arises as a complication of an underlying chronic inflammatory disease, such as rheumatoid arthritis, Crohn disease, tuberculosis, bronchiectasis, and chronic osteomyelitis. Other rare hereditary and senile forms of amyloidosis have also been described., ${ }^{2,5}$

Amyloidosis may be classified as localized with involvement of 1 organ or systemic with involvement of multiple sites according to the distribution of amyloid deposits. Localized disease is present in about $10 \%$ to $20 \%$ and most amyloidosis is systemic. ${ }^{2}$ The therapeutic approaches and prognostic implications are different. Systemic amyloidosis is progressive and usually fatal; however, supportive or localized management is suitable for localized disease. Systemic amyloidosis usually involves gastrointestinal tract, cardiac and striated muscle and adipose tissue. In the localized type of disease, abnormal proteins are confined to an organ, commonly the respiratory tract, skin or urinary tract. Localized amyloidosis is usually primary, but it can also be secondary, although this is rare. ${ }^{2,3}$

Primary localized amyloidosis of the urinary tract is a rare condition and most of the reported cases have involved the bladder. We searched English articles for MEDLINE database

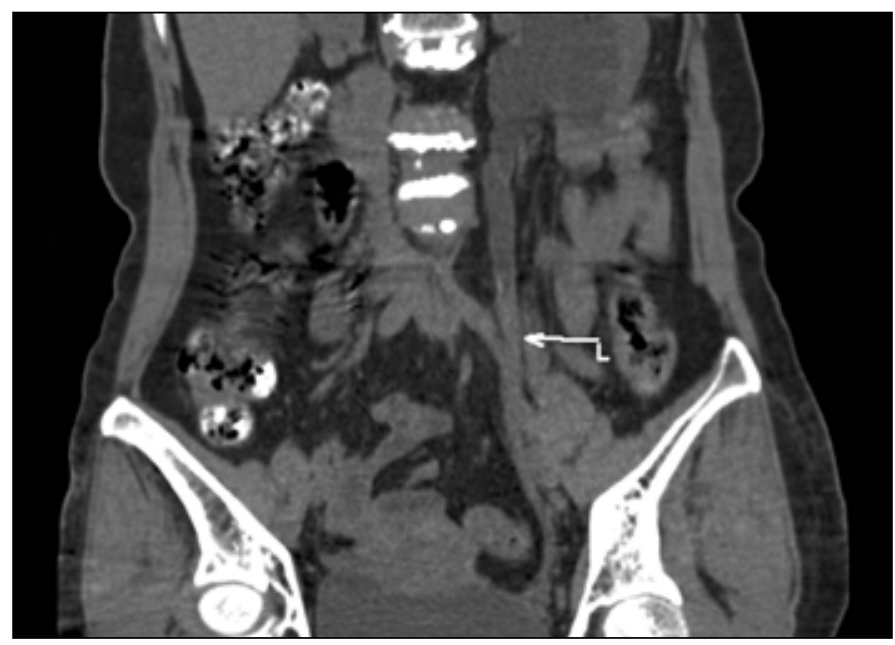

Fig. 2. A homogeneous soft tissue density mass was seen in the fifth vertebral level of the left ureter.

using the key words "ureter amyloidosis" to select papers. 86 papers were found. Based on English articles or English abstract, 45 papers ${ }^{1-45}$ and 49 cases of ureteral amyloidosis were matched. Lehmann reported the first case of localized amyloidosis of ureter in 1937. Gilbert and McDonald reported the first English literature about localized ureteric amyloidosis in $1952 .{ }^{6}$ The mean age at diagnosis of the reported cases was 58.3, and ranged from 17 to 81 . Of these cases, $72.9 \%(35 / 48)$ of patients were over 50 years old. Women were predominantly affected (32:17). The main presenting features in 30 patients $(61.2 \%)$ were loin pain. Twenty-five patients (53.1\%) were referred to hospital following hematuria. Among all cases, 7 patients (14.3\%) were bilateral. The ratio of left lesion versus right lesion was 19:24. The location of lesion was definite in 44 patients (49 sides), among which, $63.3 \%(31 / 49)$ were in lower ureter. The remaining was $22.4 \%$ and $14.3 \%$ in upper ureter and middle ureter, respectively.

Although radiological examinations, such as CT scan, intravenous pyelography and ultrasound, could detect hydronephrosis in all of the above cases, they did not indicate a specific etiology. Some authors consider the presence of calcifications as a typical sign on CT scan and intravenous pyelography. ${ }^{2}$ However, only 9 cases $(18.4 \%)$ showed calcifications on radiological findings. Moreover, calcifications can also be present in tuberculosis and schistosomiasis. ${ }^{41}$ Tsujioka and colleagues emphasized that ureteral amyloidosis should be considered when the lesion is visualized as a hypo-intensity on T2-weighted images and is not obviously associated with a mass effect; although it is noteworthy that these authors only have 2 cases in their study. ${ }^{45}$

The diagnosis of amyloid is currently based on specific Congo red staining on a biopsy of an involved organ by light microscopy under polarized light. Characteristically, the amyloid deposit shows apple-green birefringence under 


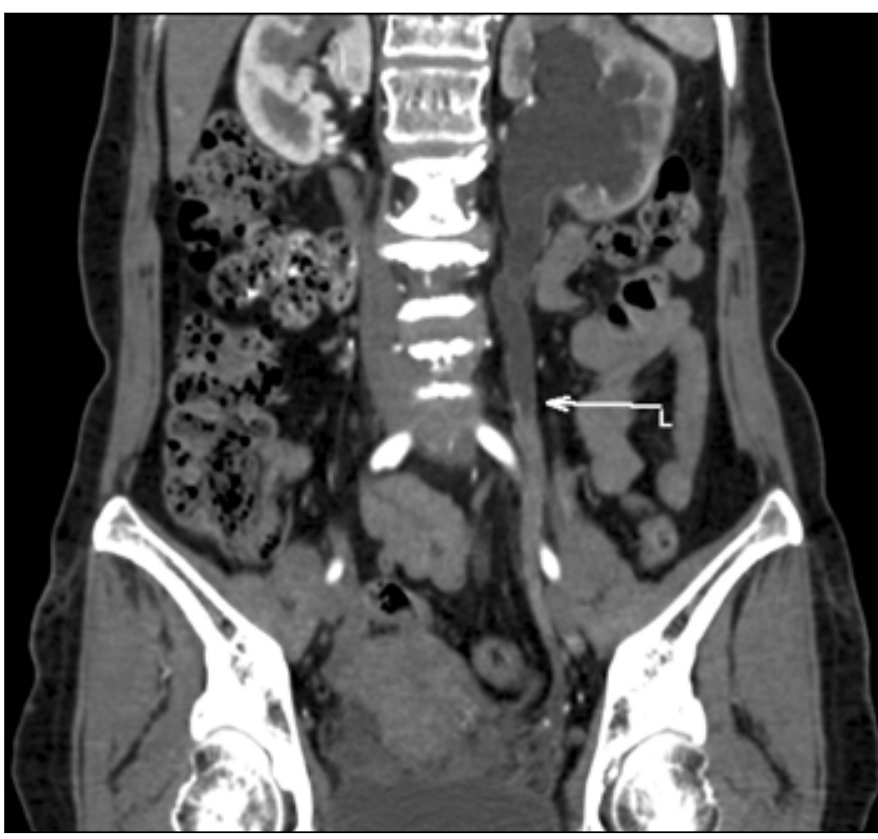

Fig. 3. Enhanced images showed a strip soft tissue density showing significant enhancement.

polarized light when stained with Congo red. The histopathologic diagnosis included AL localized amyloidosis, AA-type amyloidosis, TTR-type amyloidosis, AH type amyloidosis, A type amyloidosis. It is histochemically possible to differentiate the specific protein that makes up the amyloid by treatment with potassium permanganate $(\mathrm{KMnO} 4)$, if the deposits persist it is AL and if they disappear it is AA. If there are still doubts, it is possible to resort to immunohistochemical techniques or the electron microscope. ${ }^{4}$ Immunohistochemistry, however, can give false-negative results. ${ }^{5}$

Because of its non-specific features, the first macroscopic diagnosis is often urothelial carcinoma. The treatment in 52 sides (47 cases) was definitely clear in all 49 cases. ${ }^{5}$ Surgery was the first choice (47 sides), among which nephroureterectomy was $61.7 \%(26 / 47)$ and it was the predominant treatment. The reasons of a higher rate of nephroureterectomy were mainly because the ureteral tumour was difficult to exclude before and at surgery, and partly because the involved ureter was too extensive to salvage the ipsilateral kidney by conventional surgery. Biopsies via an ureteroscope prior to surgery or intra-operative frozen section were taken in 16 sides $(34.0 \%, 16 / 47)$ enabling the patient to be treated with other surgery instead of nephroureterectomy. The other surgery included ureteroneocystostomy $(21.3 \%$, $10 / 47)$, local excision and end anastomosis of the ureter $(6.4 \%, 3 / 47)$, ileopyelostomy $(2.1 \%, 1 / 47)$, autotransplantation $(2.1 \%, 1 / 47)$, ileal ureter $(2.1 \%, 1 / 47)$, double J stent $(2.1 \%, 1 / 47)$, ureteric re-implantation with psoas hitch $(2.1 \%, 1 / 47)$. For bilateral localized amyloidosis, correct preoperative diagnosis was necessary to preserve the kidney.

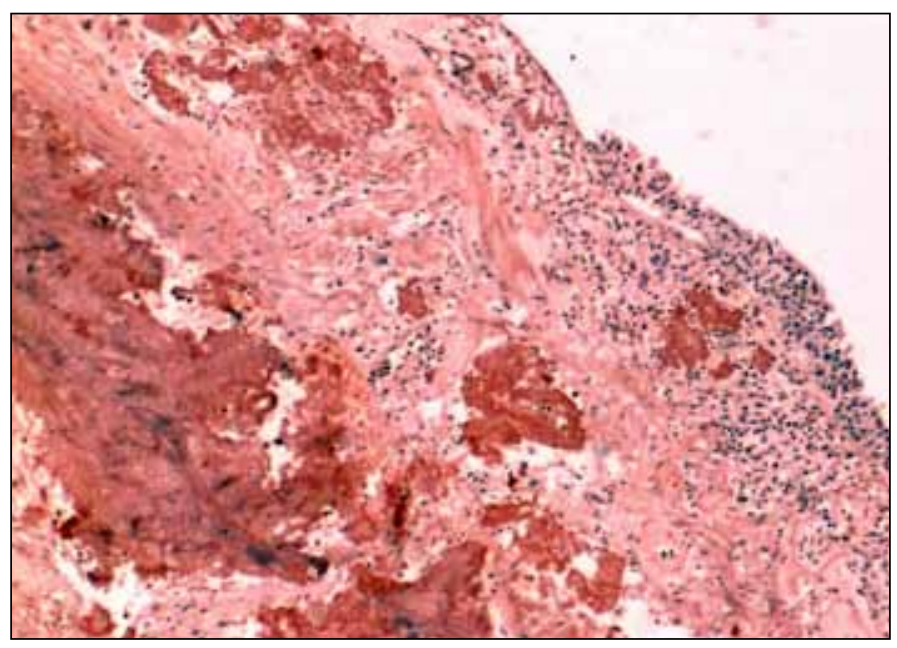

Fig. 4. Amyloid deposits in impaired ureter (Congo red stain).

After confirming the pathology by biopsy, Kato and colleagues $^{35}$ and Tsuijioka and colleagues ${ }^{45}$ treated 3 patients by gauze-dipped dimethyl sulfoxide (DMSO) applied to the skin and oral colchicine. Another non-surgery treatment was follow-up. Tudor Borza and colleagues reported 2 cases with surveillance imaging and routine follow-up, without any medical or surgical interventions. ${ }^{3}$ With follow-up of 15 months, 6 years, and 8 years, none of the patients displayed clinical or radiographic signs of progressive disease.

The pathogenesis of localized amyloidosis is unknown, but may be caused by chronic and recurrent inflammation with migration of lymphoplasmic cells and subsequent aberrant monoclonal proliferation and local secretion of light chains. ${ }^{3}$ Borza and colleagues found that the prognosis of localized amyloidosis was good. None of the patients developed progressive disease or recurrence of their symptoms during follow-up. ${ }^{3}$ Only Mullin and colleagues reported 1 case of ureteral amyloidosis associated with low-grade transitional cell carcinoma. ${ }^{19}$ Subsequent follow-up was also uneventful.

\section{Conclusion}

Localized amyloidosis of the urinary tract is a rare disease and can easily be confused with a neoplasm. The physiopathology is unknown and the prognosis is usually good. Because of its rarity and the difficulty in differentiating this condition from urothelial carcinoma by clinical manifestation and radiological images, nephroureterectomy has often been performed unnecessarily for this disease. Biopsies via a ureteroscope prior to surgery or intraoperative frozen section examination, which yielded the diagnosis of amyloidosis, could help avoid unnecessary surgery. The use of dimethyl sulfoxide or follow-up with serial imaging may become a promising treatment. 
Acknowledgements: Yujun Du, Haifeng Wang, Yanbo Wang and Yan Wang contributed equally to this work.

Competing interests: Dr. Ding, Dr. Yan and Dr. Ma, Dr. C. Wang, Dr. Du, Dr. H. Wang, Dr. Yan Wang and Dr. Yanbo Wang all declare no competing financial or personal interests.

This paper has been peer-reviewed.

\section{References}

1. Merrimen JL, Alkhudair WK, Gupta R. Localized amyloidosis of the urinary tract: case series of nine patients. Urology 2006;67:904-9. htrp://dx.doi.org/10.1016/.urology.2005.11.029

2. Kawashima A, Alleman WG, Takahashi $\mathrm{N}$, et al. Imaging evaluation of amyloidosis of the urinary tract and retroperitoneum. Radiographics 2011;31:1569-82. http://dx.doi.org/10.1148/rg.316115519

3. Borza T, Shah RB, Faerber GJ, et al. Localized amyloidosis of the upper urinary tract: a case series of three patients managed with reconstructive surgery or surveillance. J Endourol 2010;24:641-4. hittp:// dx.doi.org/10.1089/end.2009.0383

4. García-Escudero López A, Padilla Nieva J, Infante Ria-o R, et al. Localized primary ureteral amyloidosis. Arch Esp Urol 2011;64:371-5.

5. Monge $M$, Chauveau $D$, Cordonnier $C$, et al. Localized amyloidosis of the genitourinary tract: report of 5 new cases and review of the literature. Medicine (Baltimore) 2011;90:212-22. http://dx.doi. org/10.1097/MD.0b013e31821cbdab

6. Mullin EM Jr, Trostle DR, Fetzer AE, et al. Bilateral amyloidosis of the ureter associated with carcinoma. J Urol 1984;132:1181-3.

7. Higbee DR, Millett WD. Localized amyloidosis of the ureter; report of a case. J Urol 1956;75:424-7.

8. Johnson HW, Ankenman GJ. Bilateral ureteral primary amyloidosis. J Urol 1964;92:275-7.

9. Yalowitz PA, Kelalis PP. Primary amyloidosis of the ureter: report of case. J Urol 1966;96:668-70.

10. Magri J, Atkinson EA. Primary amyloidosis of the ureter. Br J Urol 1970;42:37-42. http://dx.doi. org/10.1111/i.1464-410X.1970.tb11905.x

11. Moul JW, McLeod DG. Bilateral organ-limited amyloidosis of the distal ureter associated with osseous metaplasia and radiographic calcification. J Urol 1988;139:807-9.

12. Klotz PG. Primary amyloidosis of the ureter: case report. Br J Urol 1975;47:518. http://dx.doi. org/10.1111/i.1464-410X.1975.tb06250.x

13. Lee KT, Deeths TM. Localized amyloidosis of the ureter. Radiology 1976;120:60.

14. Willén H. Primary amyloidosis of the ureter simulating malignancy. Acta Pathol Microbiol Scand A 1978:86A:357-9

15. Mariani AJ, Barrett DM, Kurtz SB, et al. Bilateral localized amyloidosis of the ureter presenting with anuria. J Urol 1978;120:757-9.

16. Yazaki T, lizumi T, Ogawa Y, et al. Renal autotransplantation for localized amyloidosis of the ureter. J Urol 1982;128:119-21.

17. Willén R, Willén $H$, Lindstedt E, et al. Localized primary amyloidosis of the ureter. Scand I Urol Nephrol 1983;17:385-9. http://dx.doi.org/10.3109/00365598309182152

18. Farrands PA, Tribe CR, Slade N. Localized amyloid of the ureter-case report and review of the literature. Histopathology 1983;7:613-22. http://dx.doi.org/10.1111/i.1365-2559.1983.tb02273.x

19. Mullin EM Jr, Trostle DR, Fetzer AE, et al. Bilateral amyloidosis of the ureter associated with carcinoma. J Urol 1984;132:1181-3.

20. Loke SL, Ma L, Yiu TF, et al. Localized amyloidosis of the ureter. Pathology 1987;19:91-4. http:// dx.doi.org/10.3109/00313028709065145
21. Suzuki T, Kikuchi K, Saito $S$, et al. A case of a primary localized amyloidosis (amyloid tumor) of the renal pelvis and ureter. Gan No Rinsho 1987;33:1494-500.

22. Moul JW, McLeod DG. Bilateral organ-limited amyloidosis of the distal ureter associated with osseous metaplasia and radiographic calcification. J Urol 1988;139:807-9.

23. Gulmi FA, Mooppan UM, Gomez-Leon G, et al. Primary localized amyloidosis of ureter. Urology 1988;32:161-4. http://dx.doi.org/10.1016/0090-4295(88)90322-6

24. Moul JW, McLeod DG. Bilateral organ-limited amyloidosis of the distal ureter associated with osseous metaplasia and radiographic calcification. J Urol 1988;139:807-9.

25. Cuckow PM, Bullock KN. Multifocal ureteric amyloidosis. Br J Urol 1991;68:207-8. http://dx.doi. org/10.1111/j.1464-410X.1991.tb15300.x

26. Yamaguchi K, Kitagawa N, Kotake T, et al. Primary localized amyloidosis of the ureter associated with osseous metaplasia. Urol Int 1991;47:164-6. http://dx.doi.org/10.1159/000282213

27. Irisawa C, Takahashi M, Suzuki K, et al. Localized amyloidosis of the ureter: a case report. Hinyokika Kivo 1991;37:73-6.

28. Callaghan P, Asklin B. Ureteral obstruction due to primary localized amyloidosis. Scand I Urol Nephrol 1993;27:535-6. http://dx.doi.org/10.3109/00365599309182290

29. Callaghan P, Asklin B. Ureteral obstruction due to primary localized amyloidosis. Scand I Urol Nephrol 1993;27:535-6. http://dx.doi.org/10.3109/00365599309182290

30. Tsui Y, Michinaga S, Ariyoshi A. lleal ureter: another option for the treatment of localized amyloidosis of the upper urinary tract. J Urol 1994;151:999-1000.

31. German KA, Morgan RJ. Primary amyloidosis of the renal pelvis and upper ureter. Br I Urol 1994;73:99100. http://dx.doi.org/10.1111/i.1464-410X.1994.tb07466.x

32. Mark IR, Goodlad J, Lloyd-Davies RW. Localized amyloidosis of the genito-urinary tract. J R Soc Med 1995;88:320-4.

33. Awakura Y, Mizutani Y, Kakehi Y, et al. A case of localized amyloidosis of the ureter. Hinyokika Kiyo 1996:42:135-8

34. Hayashi T, Koijma S, Sekine H, et al. Primary localized amyloidosis of the ureter. Int J Urol 1998;5:383-5. http://dx.doi.org/10.1111/i.1442-2042.1998.tb00373.x

35. Kato Y, Sue Y, Fujii H, et al. Localized amyloidosis of the ureter and bladder treated effectively by occlusive dressing technique therapy using dimethyl sulfoxide: a case report. Hinyokika Kiyo 2000;46:421-4.

36. Fugita OE, DeLatorre CG, Kavoussi LR. Primary localized amyloidosis of the ureter. Urology 2001;58:281 iv$281 \mathrm{l}$.

37. lida S, Chujyo T, Nakata Y, et al. A case of amyloidosis of the renal pelvis. Hinyokika Kiyo 2003;49:423-6.

38. Fushimi T, Takei Y, Touma $T$, et al. Bilateral localized amyloidosis of the ureters: clinicopathology and therapeutic approaches in two cases. Amyloid 2004;11:260-4. http://dx.doi. org/10.1080/13506120400014807

39. Kitsukawa $S$, Hosoda $S$, Otsuru N, et al. Localized amyloidosis of the ureter: a case report. Hinyokika Kiyo 2006;52:131-4

40. Okuda H, Tei N, Shimizu K, et al. Case report: a case of localized amyloidosis of the ureter [in Japanese]. Hinyokika Kiyo 2008:54:419-22.

41. Domiciano DS, de Carvalho JF. Primary localized amyloidosis of the ureter. Isr Med Assoc J 2008; 10:237-8.

42. Weiwei Z, Yi H, Jinsong Z. Primary localized amyloidosis of the ureter. Abdom Imaging 2011;36:609-11. http://dx.doi.org/10.1007/s00261-011-9694-0

43. Miyazaki Y, Kamba T, Shimizu Y, et al. A case of amyloidosis of the ureter caused by primary macroglobulinemia. Hinyokika Kiyo 2011;57:185-8.

44. Mantoo S, Hwang JS, Chiang GS, et al. A rare case of localised AA-type amyloidosis of the ureter with spheroids of amyloid. Singapore Med J 2012;53:e77-9.

45. Tsujioka $Y$, Jinzaki $M$, Tanimoto $A$, et al. Radiological findings of primary localized amyloidosis of the ureter. J Magn Reson Imaging 2012;35:431-5. http://dx.doi.org/10.1002/imri.22858

Correspondence: Dr. Yan Wang, Department of Urology, The First Hospital of Jilin University, 71 Xinmin ST, Changchun, Jilin Province, China; dingxiaobo_2008@126.com 